\title{
Clinical Profile of HIV/AIDS in Women in a Tertiary Care Centre of District Kamrup (Metro) in Assam - An Observational Study
}

\author{
Hitakalpa Baishyaํ, Kalyan Kumar Nath², Neena Nath³ ${ }^{3}$ Swaroop Kumar Baruah ${ }^{4}$ \\ 1, 2,3,4 Department of General Medicine, Gauhati medical college and hospital, Guwahati, Assam, India.
}

\section{ABSTRACT}

\section{BACKGROUND}

HIV/AIDS is a global pandemic with a national adult (15-49 yrs) prevalence of 0.22 $\%$ (NACO 2019) and females constituted around $44 \%$ of the total estimated people living with HIV (PLHIV). HIV infection in women occurs mostly in their reproductive years which leads to transmission to the child thereby comprising the most common mode of acquiring HIV infection in children $<15$ yrs. Women account for more than $70 \%$ of the caregivers of seropositive spouses or other family members. This study was conducted to explore the reasons behind increasing HIV prevalence among adult women in the region including their demographic profile, transmission dynamics and clinical profile of HIV/AIDS.

\section{METHODS}

This is a hospital-based observational study among 100 selected adult female patients with HIV/AIDS (as per NACO guidelines) who attended the Gauhati Medical College Hospital from $1^{\text {st }}$ July 2016 to $30^{\text {th }}$ June 2017. A detailed clinical history of the selected cases was obtained in the register of the institutional ICTC centre and was recorded in standard proforma.

\section{RESULTS}

Out of the 100 cases included in the study, 95 were married of which 74 had seropositive husbands while 21 were discordant couples. The mean age of the study population was $31.27 \pm 9.7$ yrs., with the majority of women being in the age group of 21 - 30 yrs. Among the study group, 13 were illiterates while 6 were graduates. Fever was the most common presenting feature with $59 \%$ followed by weight loss (36\%) and diarrhoea (15\%) respectively. Bacterial respiratory tract infection and oral candidiasis were present in $12 \%$ and $11 \%$ of patients respectively as opportunistic infections.

\section{CONCLUSIONS}

The majority of cases in our study were housewives and the biggest risk was through heterosexual sex with their husbands or primary partners. Only a few attended colleges in the study group while the rest were either illiterates or school dropouts and the majority of them didn't have comprehensive knowledge of HIV/AIDS. The large gender inequality in education and unemployment may be responsible for the spread of HIV/AIDS in women.
Corresponding Author: Dr. Kalyan Kumar Nath, Assistant Professor, Department of General Medicine, Gauhati Medical College and Hospital, Bhangagarh, Guwahati - 781032, Assam, India.

E-mail: kalyannath@tyahoo.com

DOI: $10.14260 / j e m d s / 2021 / 803$

How to Cite This Article:

Baishya H, Nath KK, Nath N, et al. Clinical profile of HIV/AIDS in women in a tertiary care centre of district Kamrup (Metro) in Assam - an observational study. J Evolution Med Dent Sci 2021;10(45):3978-3982, DOI: 10.14260/jemds/2021/803

Submission 05-03-2021, Peer Review 10-05-2021, Acceptance 21-12-2021, Published 28-12-2021.

Copyright (c) 2021 Hitakalpa Baishya et al. This is an open access article distributed under Creative Commons Attribution License [Attribution 4.0 International (CC BY 4.0)]

\section{KEY WORDS}

Clinical, HIV/AIDS, Women 


\section{BACKGROUND}

HIV/AIDS is a global pandemic with a national adult (15 - 49 yrs) prevalence of $0.22 \%$ (NACO 2019) ${ }^{1}$ and females constituted around $44 \%$ of the total estimated people leaving with HIV.

\section{HIV Scenario at Global \& National Level ${ }^{2}$}

At the end of 2015, globally there were an estimated 36.7 million (34.0 million - 39.8 million) people living with HIV. 2.1 million people (1.8 million - 2.4 million) were infected newly with HIV and 1.1 million $(9,40,000-1.3$ million) people died of AIDS-related illness during 2015 [UNAIDS Fact sheets November 2016]. The reports also state that globally new HIV infections among children have declined by $50 \%$ since 2010 but no decline among adults and AIDSrelated deaths have fallen by $45 \%$ since the peak in 2005 . By June 2016, UNAIDS estimated that 18.2 million people were accessing antiretroviral therapy, up from 15.8 million in June 2015 and 7.5 million people in 2010. Based on the significant progress in the control of the HIV epidemic globally, the world committed to end the AIDS epidemic on a fast track mode by 2030 as part of the sustainable developmental goals (SDGs) that were adopted at the UN General Assembly last year.

The Indian HIV epidemic has been defined as a concentrated non-IDU epidemic in all the states except Manipur and Nagaland, where the epidemic is defined as a concentrated IDU epidemic. As per the Technical Report on India HIV estimates 2015, the adult HIV prevalence in India was estimated as $0.26 \%$ in 2015 and it had shown a steady decline from $0.38 \%$ in 2001-03.

However, while the decline in adult HIV prevalence and annual new HIV infections is sustained in the high prevalence states, the rising trend in new HIV infections is noted among adults during 2007-15 in a few low prevalence states.

\section{HIV Scenario at the Regional Level ${ }^{2}$}

The north-eastern part of India comprises some high and low HIV prevalence states. Manipur has shown the highest estimated adult HIV prevalence in the country at $1.15 \%$ in 2015. The other high prevalence states in the region included Mizoram (0.80 \%) and Nagaland (0.78\%). Similar to the rest of the country, these high prevalence states have shown a declining trend in HIV prevalence whereas some of the low prevalence states are showing a rising trend in recent years.

\section{HIV Scenario in Assam²}

Assam is categorized as a low HIV prevalence state with an estimated adult HIV prevalence of $0.06 \%$ which is lower than the National Prevalence of $0.26 \%$. However, the adult HIV prevalence in the state has increased from $0.04 \%$ in 2007 to $0.06 \%$ in 2015. It was estimated that Assam had 928 new HIV infections in 2015 (NACO Technical Report 2015). The report also states that Assam had an estimated 12,090 people living with HIV (PLHA) in 2015. However, as per Programme Data, 13368 no. of HIV positive cases were diagnosed till 31st March 2017 out of which 9851 cases were enrolled under ART and 4698 cases are presently alive and on ART. Assam is also a highly vulnerable state for HIV transmission because of the following reasons:

1. It is the gateway of the north-eastern states.

2. It is surrounded by three high prevalence states of Manipur, Mizoram and Nagaland.

3. A large number of young population from the state is going to large cities for employment and getting involved in high-risk behaviour.

4. Assam has a large private health sector that caters to all the north-eastern states.

5. A large number of female migrants from other northeastern states, West Bengal and Nepal who come to Assam for employment and education get involved in risk behaviour favourable for HIV transmission.

The HIV sentinel surveillance data of the 2010-11 and 2015 rounds show that the HIV epidemic in the state was concentrated among high-risk groups- IDU (1.46\%), MSM $(1.40 \%)$ and FSW (0.46 \%) while HIV prevalence among ANC clinic attendees, considered proxy for the general population, was low at $0.18 \%$. However, as there is no migrant or trucker HIV sentinel site in Assam, there is no available data from HIV sentinel surveillance on the bridge population and its possible role in the spread of infection from the high-risk groups (HRGs) to the general population. When the data of HIV detection in Assam is analyzed by route of transmission, it is observed that the main route of transmission is heterosexual $(86.6 \%)^{2}$

An estimated 86 thousand new HIV infections occurred in India in 2015, showing a $66 \%$ decline in new infections from 2000 and a $32 \%$ decline from 2007, the year set as the baseline under the National AIDS Control Program-Phase IV (NACP-IV). However, it is important to note that while the new HIV infections among adults decreased considerably in the so-called "high-prevalence" states, increasing trends of new infections were noted in some "low-prevalence" states. Thus, one of the most important challenges under the NACP concerns the emergence of newer vulnerable areas/groups within the country and timely and efficient control of the HIV situation in such vulnerable pockets. ${ }^{3}$

The north-eastern state of Assam is one such example, which has long been considered as one of the low HIV prevalence states in India. However, the total number of HIV/AIDS cases in the state has increased steadily since 2007, and it nearly doubled to an estimated 12,090 cases in 2015 during these eight years. The HIV prevalence among adult population also increased by $50 \%$ from $0.04 \%$ in 2007 to $0.06 \%$ in 2015 . More importantly, the long-term trend of HIV prevalence appears to be rising among the antenatal clinic (ANC) attendees that serve as a proxy for HIV prevalence among the general population. Unless the reasons for this alarming increase are explored timely and appropriate control measures are taken, such a situation may pave the way for a generalized HIV epidemic in the state. ${ }^{3}$ In Assam, 85 $\%$ of HIV infections are reportedly transmitted through heterosexual routes. A recent study conducted on the HIV positive clients detected in Assam Medical College, Dibrugarh, also highlighted that heterosexual contact and non-use of contraceptives were the major high-risk behaviours for HIV transmission. Notably, the use of modern contraceptive 
practices has always been very low among all the states in India, with the use of traditional birth control methods being the highest in Assam. Thus, the increasing trend of HIV prevalence among married women could occur through the clients of the FSWs. However, the role of several other risk groups and/or risk factors cannot be ruled out, since sufficient data were unavailable under the HSS to ascertain the trend of HIV prevalence among men who have sex with men (MSM) and no data were available for the bridge populations like the migrants and long-distance truckers in Assam. Although migration from Assam has not been as huge as in some of the highest recognized "migration corridors" in the country, there has been considerable in/out migration into/from the state for various reasons, especially from the rural/impoverished sections of the population. ${ }^{3}$

Even after 26 years since the first case of AIDS was reported in Assam, comprehensive knowledge of HIV/AIDS among women in the age bracket of 15 - 49 years is minimal as per the latest National Family Health Survey (2015-16) report that was released recently. 4 The NFHS report in one of its key indicators under the knowledge of HIV/AIDS among adults, reported that 9.4 per cent of women in the age group of 15 - 49 years had comprehensive knowledge about HIV/AIDS. The term 'comprehensive knowledge of HIV/AIDS' as per the report is defined as knowing about reducing the chance of getting HIV/AIDS through consistent use of condoms on every sexual occasion and having just one uninfected faithful sexual partner. The report also defines it as having knowledge that a healthy-looking person can have HIV/AIDS, and rejecting the two most common misconceptions about transmission or prevention of HIV/AIDS. ${ }^{4}$

\section{Objectives}

This study was conducted to explore the reasons behind increasing HIV prevalence among adult women in the region including their demographic profile, transmission dynamics and clinical profile of HIV/AIDS.

\section{METHODS}

This is a hospital-based prospective observational study conducted among 100 HIV positive adult patients attending the ICTC (Integrated counselling and testing centre) of Gauhati Medical College and Hospital, Guwahati, Assam from $1^{\text {st }}$ July 2016 to $30^{\text {th }}$ June 2017 . The study employed one quantitative data collection procedure.

Basic socio-demographic information, as well as risk categories and HIV test results, were captured anonymously in the registers of the institute, where one year's data was extracted from the ICTC centre. Collection of structured questionnaire-based quantitative data was done through face-to-face interviews from the consenting ICTC women attendees (who attended during the year) as well as their spouses to explore sexual and other risk behaviours and practices in greater detail; in addition, migration-related history of the spouses of the married women attendees was obtained. All participants were aged more than 15 years.

\section{Inclusion Criteria}

HIV positive adult women as per National AIDS Control Organization (NACO) guidelines, who were above 15 years of age and not started on ART (ART Naive).

\section{Exclusion Criteria}

All HIV positive patients under 15 years of age.

\section{Ethical Statement}

The study was undertaken after taking informed consent from the patients and clearance from the ethical committee. This research project was approved by the Institutional Ethics Committee of Gauhati Medical College vide approval letter no. MC/217/2016/137 dated 01/09/2016. In addition, for extracting existing data from the ICTC registers, approval was taken from the Data Sharing Committee of the Assam State AIDS Control Society as per the NACO Data Sharing Guidelines, 2015. Informed consent was taken from each client while collecting quantitative or qualitative data. Strict confidentiality of all data was maintained and no personal identifiers were used in the analysis.

\section{Statistical Analysis}

GraphPad InStat software was used for statistical analysis. Pvalue $<0.05$ was considered significant. The extracted program data as well as quantitative data collected through structured interviews were entered into a pre-designed computerized database using MS-Excel. Following data cleaning and editing, descriptive analyses were carried out using GraphPad InStat statistical software version 3.1.

\section{RESULTS}

\section{Age Distribution}

The maximum number of patients were in the age group of 21-30 years (50 cases) followed by 31-40 years (25 cases) whereas, only 15 patients were above 40 yrs of age. Thus, it was found that most of the patients belonged to the reproductive age group.

\begin{tabular}{|ccc|}
\hline Age in Years & No. of Cases & Percentage \\
$15-20$ & 10 & 10 \\
$21-30$ & 50 & 50 \\
$31-40$ & 25 & 25 \\
$41-50$ & 10 & 10 \\
$>50$ & 5 & 5 \\
\hline & Table 1. Age Distribution \\
\hline
\end{tabular}

\section{Marital Status}

95 out of 100 cases were married at the time of being diagnosed with HIV/AIDS, while 5 were unmarried.

\begin{tabular}{|ccc|}
\hline Marital Status & No. of Cases & Percentage \\
Married (females) & 95 & 95 \\
Unmarried (females) & 5 & 5 \\
\hline \multicolumn{3}{|c}{} \\
\hline
\end{tabular}


Educational Status, occupation and Comprehensive Knowledge of HIV/AIDS

50 out of 100 patients went to secondary school education while 31 studied up to primary level only. 13 of them had not received any formal education. 78 out of 100 were housewives while only 12 of 100 were either self-employed or working as government or private servants. The majority of the patients didn't have comprehensive knowledge of HIV/AIDS while only 10 of 100 patients (10\%) were found to have comprehensive knowledge of HIV/AIDS during a faceto-face interview.

\begin{tabular}{|ccc|}
\hline Educational Status & No. of Cases & Percentage (\%) \\
Illiterate & 13 & 13 \\
Primary school & 31 & 31 \\
Secondary school & 50 & 50 \\
College and above & 6 & 6 \\
\hline \multicolumn{2}{c}{ Table 3. Educational Status } \\
\hline
\end{tabular}

\section{Clinical Presentation}

It was varied in the study group. Fever was the most common presenting symptom found in 59 cases, followed by weight loss in 36 cases, diarrhoea in 15 cases, cough in 22 cases, anorexia in 11 cases, malaise in 4 cases while the number of asymptomatic cases was 13 . However, among the cases studied, 72 patients had more than one presenting complaint at the time of diagnosis.

\begin{tabular}{|ccc|}
\hline Presenting Features & No. of Cases & Percentage (\%) \\
Weight loss & 36 & 36 \\
Fever & 59 & 59 \\
Diarrhoea & 15 & 15 \\
Cough & 22 & 22 \\
Anorexia & 11 & 11 \\
Malaise & 4 & 4 \\
Asymptomatic & 13 & 13 \\
\hline \multicolumn{2}{c}{ Table 4. Clinical Presentation } \\
\hline
\end{tabular}

\section{Incidence of Opportunistic Infections (OI)}

Out of 100 patients, 33 had opportunistic infections. Of these, 5 patients had more than one OI. Bacterial respiratory tract infection (12\%) was the most common OI seen which was followed closely by candidiasis $(11 \%)$ and tuberculosis (9 $\%)$.

\begin{tabular}{|ccc|}
\hline Opportunistic Infections & Number of Cases & Percentage (\%) \\
Tuberculosis & 9 & 9 \\
Candidiasis (Oral+Oesophageal) & 11 & 11 \\
Bacterial Respiratory Tract Infections & 12 & 12 \\
Diarrhoea & 6 & 6 \\
Herpes zoster Infections & 2 & 2 \\
Folliculitis & 1 & 1 \\
\hline Table 5. Incidence of Opportunistic Infections(OI) \\
\hline
\end{tabular}

\section{Opportunistic Infection in Relation to CD4 Count}

CD4 count in patients with OI ranged from 19 to 637 cells $/ \mathrm{mm}^{3}$. The median CD4 count in those with OI was 154 cells $/ \mathrm{mm}^{3}$ while in those without OI was 392 cell $/ \mathrm{mm}^{3}$ which is statistically significant $(\mathrm{P}<0.05) .33$ patients had some form of OI, of which 22 cases had CD4 counts $\leq 200$ cells $/ \mathrm{mm}^{3}$.

\begin{tabular}{|cc|}
\hline Presence of OI & Median CD4 Count \\
Median CD4 count with OI & 154 \\
Median CD4 count without OI & 397 \\
P Value & $<0.05$ \\
\hline Table 6. Opportunistic Infection in Relation to CD4 Count \\
\hline \multicolumn{2}{|c|}{ (Unpaired t-test was used as a test of significance) } \\
\hline
\end{tabular}

\section{DISCUSSION}

In the present study, $75 \%$ of cases were in the age group of 21-40 yrs. This is similar to other studies by Deivanayagam CN et al. ${ }^{5}$ (2001) and Nair SP et al. ${ }^{6}$ (2003) who reported $71.94 \%$ and $77.68 \%$ of HIV cases to be in the age group of 21-40 years respectively. Siddharth Rao PS7 2016 reported that the highest prevalence of HIV occurred in the median age of 35 yrs.

In the present study, most of the women (95\%) were married and contracted HIV infection through heterosexual route from their seropositive husbands, which was consistent with John TJ et al. ${ }^{8}$ (1993) and Kumar A et al. ${ }^{9}$ (2008) who found $80 \%$ and $84.1 \%$ of married females respectively in their studies.

As per the present study, $44 \%$ of women did not attend secondary school, that is $2 / 5^{\text {th }}$ were either illiterate or went to primary school only which was similar to the worldwide data of least developed countries, where $60 \%$ of girls affected with HIV had not attended secondary school. ${ }^{10}$ Research has shown a direct correlation between girls' educational attainment and HIV risk: uneducated girls are twice as likely to acquire HIV as those who have attended school.11

Only $10 \%$ of the patients were found to have comprehensive knowledge of HIV/AIDS which was similar to the National Family Health Survey Report, 2015-16.

In the present study, the most commonly affected group was that of the housewives (78 cases). This finding was similar to Jayarama S et al. ${ }^{12}$ (2008), Kumar A et al. ${ }^{9}$ (2008) and Darbastwar $\mathrm{M}^{13}$ (2011) who also reported a high prevalence of HIV among housewives with $27 \%, 34.2 \%$ and $49.2 \%$ in their studies respectively. The higher prevalence of HIV among housewives was probably due to the high-risk behaviour of their spouses.

Weight loss was seen in $36 \%$ of cases in the present study, which is consistent with Goel V et al. ${ }^{14}$ (2016) who found weight loss in $41 \%$ of his cases.

In the present study, lower respiratory tract infection was seen in $12 \%$ of cases. Patil VC et al.15 (2016) found community-acquired pneumonia in $32.69 \%$ of cases. Chakraborty J et al. ${ }^{16}$ (2006) reported candidiasis in $20.3 \%$ of cases in his study which was nearly similar to the present study with $11 \%$ cases.

Tuberculosis was the most common OI in most of the Indian studies whereas in the present study only $9 \%$ had tuberculosis. The discrepancy in the proportion of cases might be because of the small size of the present study group and the lack of data based on women with HIV in our population.

In the present study, 33 patients had some form of OI, of which 22 cases had CD 4 counts $\leq 200$ cells $/ \mathrm{mm}^{3}$. The median CD 4 count in those with OI was 154 cells $/ \mathrm{mm}^{3}$ while in those without OI was 392 cell $/ \mathrm{mm}^{3}$ which is statistically significant $(\mathrm{P}<0.05)$. In a study by Takalkar A $\mathrm{A}^{17} 2012$, OI was seen in $70.5 \%$ cases with CD4 count less than $200 / \mathrm{mm}^{3}$ which was consistent with the present study. 


\section{CONCLUSIONS}

The number of women living with HIV is growing. In the present study, the majority of cases were found to be housewives and the biggest risk was through heterosexual sex with their husbands or primary partners. Only a few attended colleges in the study group while the rest were either illiterates or school dropouts. The large gender inequality in education and unemployment was responsible for the spread of HIV/AIDS in women. About one-third of the patients had already developed opportunistic infections at the time of diagnosis of which respiratory tract infections and candidiasis were the most common.

Data sharing statement provided by the authors is available with the full text of this article at jemds.com.

Financial or other competing interests: None.

Disclosure forms provided by the authors are available with the full text of this article at jemds.com.

\section{REFERENCES}

[1] NACO 2019: India HIV estimates 2019 report.

[2] Assam State AIDS Control Society. HIV Scenerio in Assam. Government of Assam, Department of Health \& Family Welfare https://asacs.assam.gov.in/portlets/hivscenerio-in-assam

[3] Bhattacharjya C, Pathak G, Mahanta T, et al. Emerging HIV Epidemic in the North-Eastern State of Assam, India: an exploratory study using mixed-methods approach. World Journal of AIDS 2018;8(1):21-36.

[4] 26 years on, women in Assam still 'ignorant' about HIV. Guwahati News - Times of India https://timesofindia.indiatimes.com/city/guwahati/26years-on-women-in-assam-still-ignorant-abouthiv/articleshow/52756234.cms

[5] Deivanayagam CN, Rajasekaran S, Senthilnathan V, et al. Clinico- radiological spectrum of tuberculosis among HIV seropositives- A Tambaram study. Indian J Tuberculosis 2001;48(3):123-7.
[6] Nair SP, Moorty KP, Suprakasan S. Clinicoepidemiological study of HIV patients in Trivandrum. Indian J Dermatol Venereol Leprol 2003;69(2):100-3.

[7] Siddharth Rao PS, Bajpai S, Pandey P, et al. Profile of seropositives visiting a HIV screening centre of a tertiary care teaching institute in north India. Int J AIDS Res 2016;3(1):46-50.

[8] John T], Babu PG, Saraswathi NK, et al. The epidemiology of AIDS in the Vellore region, southern India. AIDS 1993;7(3):421-4.

[9] Kumar A, Kumar P, Gupta M, et al. Profile of clients tested HIV positive in a voluntary counseling and testing centre of a district hospital, Udupi, South Kannada. Indian J Community Med 2008;33 (3):156-9.

[10] Women and HIV- a spotlight on adolescent girls and young women. UNAIDS 2019: p. 16.

[11] Women and HIV- a spotlight on adolescent girls and young women. UNAIDS 2019: p. 15.

[12] Jayarama S, Shenoy S, Unnikrishnan B, et al. Profiles of attendees in voluntary counseling and testing centers of a medical college in coastal Karnataka. Indian J Comm Med 2008;33(1):43-6.

[13] Darbastwar M, Kangule D, Kokiwar P. Profile of HIV positive attendees at integrated counseling and testing centre of a medical teaching institutute in Andhra Pradesh, India. Int J Biol Med Res 2011;2(4):862-4.

[14] Goel V, Kumar D, Patwardhan V, et al. Trends of seroprevalence, epidemiology and clinical presentation of HIV in North India: a tertiary care hospital based study. World Journal of AIDS 2016;6:54-8.

[15] Patil VC, Patil HV. Clinical manifestations and outcome of patients with human immunodeficiency virus infection at tertiary care teaching hospital. Indian J Sex Transm Dis 2016;37(1):38-45.

[16] Chakravarty J, Mehta H, Parekh A, et al. Study on clinicoepidemiological profile of HIV patients in Eastern India. J Assoc Physicians India 2006;54:854-7.

[17] Takalkar AA, Saiprasad GS Prasad VG, et al. Study of oppurtunistic infections in HIV seropositive patients admitted to community care centre (CCC), KIMS Narketpally. Biomed Res 2012;23(1):139-42. 